\title{
MAKING TEACHING AS INCLUSIVE AS POSSIBLE
}

IT'S COMMONLY KNOWN THAT MANY FIELDS OF STEM, IN PARTICULAR ENGINEERING AND COMPUTER SCIENCE, SUFFER FROM A LACK OF DIVERSITY. TACKLING THIS IS A MAJOR CHALLENGE, SO DR CHRISTINA H. PAGUYO AND DR VALENTINA ITURBELAGRAVE, FROM THE UNIVERSITY OF DENVER IN THE US, ARE USING INNOVATIVE SOCIAL SCIENCE TO HELP TEACHERS EMBRACE INCLUSIVE TEACHING TECHNIQUES

\section{TALK LIKE A SOCIAL SCIENTIST}

DEI - Diversity, Equity and Inclusion, to prevent marginalisation of under-represented groups

INCLUSIVE TEACHING - embraces students as whole beings to create relevant, meaningful, and accessible learning experiences that recognise students' differences as enriching sources of diversity

INTERSECTIONALITY - understanding the complex power dynamics of how a person's multiple social identities intersect to affect their whole lives

LGBTQIA - lesbian, gay, bisexual, transgender, queer/questioning, intersex and asexual

POSITIONALITY - understanding how people's social position shapes their identities and the power they hold in certain contexts

PRIVILEGE - the benefits and advantages given to those whose social identities are shared with the dominant culture
OPPRESSION - the systematic and systemic suppression of a group by the group in power

QUALITATIVE DATA - observational or narrative data that explains and characterises, collected through (for example) field notes, video recordings, interviews or focus groups

QUANTITATIVE DATA - numerical data that can be used for calculations and statistical analysis

\section{SOCIAL DESIGN EXPERIMENTS}

partnerships between researchers and (for example) teachers that facilitate learning and development through an evolving design and measure process

SOCIAL SCIENCE - the study of human society and social relationships

the life-experiences and identities of students," says Valentina.

\section{INCLUSIVE TEACHING}

Valentina and Christina are spearheading inclusive teaching and assessment initiatives. This is a method of teaching rooted in the understanding that everyone in a classroom brings their values, cultures, genders and ethnicities with them, and these have an impact on the learning experience.

"Think about all the different parts of your identity and how they combine to make up your whole self," says Valentina. "These are your intersecting social identities. For example, I am a cisgender, female scholar and also a mother of four." Your intersecting social identities shape how you engage with learning - for instance, you might have experience of cultures, languages, disability, or discrimination that others do not.

"These factors influence how people make meaning and learn about the world around them," adds Valentina. "For example, you might have more insight into accessibility if you have a physical condition, or different conceptual processing if you speak another language." An important starting point for Valentina is that, "everything we learn is processed through the lens of our social identities, and many of these identities change over time, that is called positionality." You may have been born as an able-bodied individual and survive an illness or accident that changes your mobility later in life. This is a positionality change because your social identity now includes your perspective as a differently-abled bodied person.

Passionate about inclusive teaching and determined to tackle challenges with optimism and collaboration, Dr Christina H. Paguyo and Dr Valentina Iturbe-LaGrave, of the University of Denver in the US, lead a National Science Foundation-funded research project designed to make engineering and computer science more inclusive through transforming the way it is taught. The first aim of this programme is to train professors to become stronger, more inclusive teachers, to help all students to become more successful. "The second aim of our research is to help professors and students understand how diversity, equity and inclusion (DEI) bolster engineering and computer science professions," says Christina. "We accomplish this through re-designing aspects of the curricula to include critical aspects of DEI that validate 
1 If you come across someone in a career that interests you, consider sending them a professional email asking if they would give you insights into their career pathway. Though it may feel uncomfortable to reach out, such contact can help you understand the pathways available and begin growing your network.

\section{Don't feel you have to follow in anyone's footsteps. Follow your heart and harness the wisdom of the people and resources you find along the way.}

3 Think outside the box, and don't be deterred by any challenges you come across.

\section{SOCIAL SCIENCE}

While social scientists can study both qualitative and quantitative data, Christina and Valentina tend to focus on qualitative data. "Researchers who study qualitative data are trained to analyse how people make meaning of processes and situations," says Christina. This sort of data can uncover very important insights that are challenging for quantitative data to capture.

This approach is seen in their work on social design experiments. "Designing for equity is the goal of these experiments. We create interdisciplinary partnerships where researchers and partners study teaching and learning through an ongoing and repetitive process of design, measurement and feedback," says Christina. "These tools help researchers design educational systems where DEI values support student learning."

\section{THE RESEARCH}

Firstly, Christina and Valentina recorded interactions in the classroom and interviews with the class professor, and then played the recordings back for the professor to reflect on. Secondly, they took field notes to complement the recordings and interviews. By working together, the researchers and professors used the video to identify the teaching strategies in play, any barriers to DEl inadvertently fostered, and where there was capacity for improvement.

"Through watching themselves teaching and through prompts that promoted self-reflection, professors were able to identify critical issues in their classrooms," says Valentina.

\section{OUTCOMES}

"There were two significant findings from our research," says Christina. "First, that universities need to create optimal conditions for professors to learn, as well as students, to help them become better teachers. Second, that DEI issues can come alive in any academic discipline, even computer science and engineering."

A lack of diversity in these fields has led to some major oversights in recent years. For instance, early facial recognition software did not recognise the faces of black people. "Even though these seemingly objective professions may appear to be neutral and solely technical, scientists and engineers can unintentionally create discriminatory infrastructures if they do not engage with DEl," says Christina.

Facilitating honest conversation and genuine self-reflection, Christina and Valentina's inspiring work reminds us that we all have a role to play in making communities - including those in academia - more inclusive. We can learn together to succeed together.

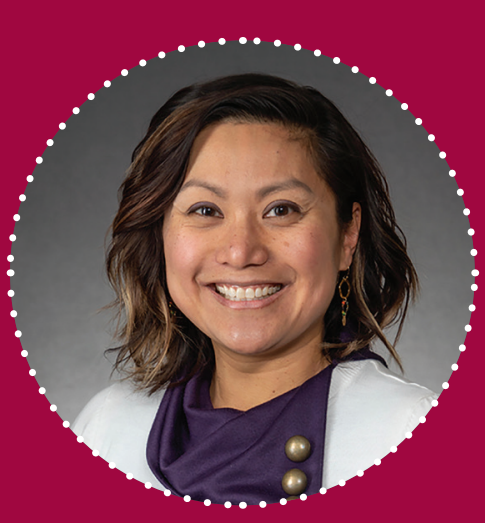

DR CHRISTINA H. PAGUYO

Director of Academic Assessment, University of Denver, USA.

\section{FIELD OF RESEARCH}

Assessment, Learning Sciences, Education Policy, DEI

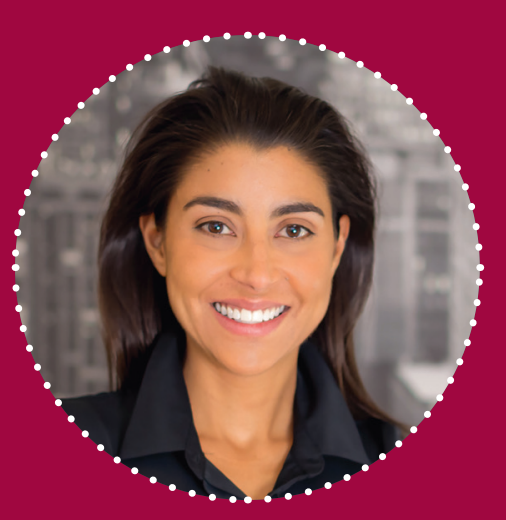

\section{DR VALENTINA ITURBE-IAGRAVE}

Director of Inclusive Teaching Practices, University of Denver, USA

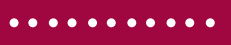

\section{FIELD OF RESEARCH}

Inclusive Teaching Practices; Power,

Privilege and Oppression; Change Leadership.

\section{JOINT RESEARCH PROJECT}

Cultivating Inclusive Identities of Engineers and Computer Scientists: strengthening faculty competence in inclusive pedagogies through formative

assessments of video records.

\section{FUNDERS}

National Science Foundation, Interdisciplinary Research Institute for the Study of (in)Equality (IRISE) 


\section{ABOUT ACADEMIC ASSESSMENT}

ACADEMIC ASSESSMENT, CHRISTINA'S SPECIALTY, IS THE PROCESS OF USING EVIDENCE TO UNDERSTAND AND IMPROVE STUDENT LEARNING IN ACADEMIC PROGRAMMES. IT CAN BE USED TO SEE WHETHER TEACHING TECHNIQUES FULFIL THEIR INTENDED PURPOSE, AND WHETHER THERE ARE ANY UNADDRESSED 'GAPS' IN THE LEARNING EXPERIENCE. CHRISTINA EXPLAINS WHY ACADEMIC ASSESSMENT HAS A CRUCIAL PLACE WITHIN TEACHING.

Assessment can be transformative because it illuminates information that would otherwise remain in the shadows. From our video consultation research, for example, assessment helped a professor see how he unintentionally fostered racially segregated teams through the use of implicitly biased technology. In this case, assessment helped 'transform' how the professor perceived students and he used DEI to re-design teams.

Traditional academic assessment focuses on learning outcomes, whereas inclusive assessment focuses on how professors can foster stronger relationships so students can engage in deep learning. Students need to be able to connect with academic content, their classmates, the teacher, and their future selves. Inclusive assessment helps build these connections, beginning with enabling professors to view students as complete human beings with dynamic and multi-faceted lives beyond the classroom.

We need to train engineers and computer scientists to understand how their designs affect all communities in society, particularly populations who are economically and politically vulnerable. We need to increase the number of Black, Indigenous and People of Colour (BIPOC), women, LGBTQIA, and people with disabilities within engineering and computer science, in particular in leadership, activist, and technical roles. We also need to train scientists how to value and collaborate meaningfully with people from all backgrounds so that STEM continues growing into a human-centred profession dedicated to improving people's lives. Together, these will ensure there is a diversity of perspectives and a socially-minded driving force shaping the future of STEM.

My passion is to help people thrive and learn with their head, hands and hearts. I enjoy building and sustaining meaningful relationships with people, because what we can create through collective endeavours is much greater than what any one individual can do alone. What I find most challenging is navigating political landscapes when stakeholders have conflicting motives, or when people have stereotypes about assessment that I work hard to dismantle. But, I also find this motivating because I love problem-solving and figuring out how to transform challenges into opportunities, like turning lemons into lemonade!

\section{ABOUT INCLUSION}

\section{INCLUSION REFERS TO MAKING} SURE THAT PEOPLE FROM ALL BACKGROUNDS ARE INCLUDED WITHIN SOCIETAL STRUCTURES, SUCH AS IN CLASSROOM LEARNING AND ACADEMIA. THIS IS BENEFICIAL NOT ONLY FOR PEOPLE FROM UNDERREPRESENTED BACKGROUNDS, BUT ALSO FOR SOCIETY AS A WHOLE, AS IT ENCOURAGES A GREATER DIVERSITY OF KNOWLEDGE AND APPROACHES TO PROBLEMS. VALENTINA TALKS ABOUT THE IMPORTANCE OF CREATING A MORE INCLUSIVE LEARNING ENVIRONMENT WITHIN ACADEMIA.

As a social scientist, I believe we best measure success through sustained culture shifts and academic changes. For example, nowadays there is a very open conversation about the lack of women in STEM fields such as computer science and engineering. This is an important conversation that is critical to moving the needle in the direction of a more diverse and inclusive workforce. We are also welcoming a vibrant generation of STEM students and professionals who are committed to making the field more inclusive and accessible. Still, we have a long way to go, and we must work together to ensure that we do not exclude anyone who can make a valuable contribution.

Barriers to inclusion manifest in many forms. Bias, microaggressions, exclusion, gendered classroom interactions, and non-diverse curricula are all still present in academia. For instance, the information taught in classes may exclude or misrepresent particular social identities, which is effectively a form of oppression. Think about the scientists and engineers you see in media, and how often your study interests are validated by people that look like you.

I am very proud of our work at the University of Denver. Our inclusive teaching programming portfolio has blossomed and now includes an open-access website that gives information on all the best tools and approaches to teaching inclusively. We have also launched a compulsory online course for faculty that covers the principles of inclusive teaching.

It's important to remember that teaching and learning are sciences in themselves. Everything you learn is filtered through the identities you claim at any given time in your life; being curious about inclusion will expand your understanding of what you need to develop and ultimately succeed.

I am most motivated by leaving the world a little better than I found it. I hope to make way for future generations of scholars who will arrive in education with an understanding of how DEI permeate every aspect of our life. We need to equip ourselves with tools to identify these issues, and work towards a world where collaboration and understanding across differences in identity is embraced. 


\section{HOW DID CHRISTINA BECOME AN EXPERT IN ACADEMIC ASSESSMENT?}

As a child, I loved asking questions and finding answers in encyclopedias (in the days before the internet)! I read voraciously and especially loved reading stories about people with superpowers, like Roald Dahl's 'Matilda'. I imagined everybody had superpowers that could be unlocked and activated to make the world a better place.

I studied English at university and became an administrator providing career counselling and leadership training for college students. During this time, I stumbled across research articles about assessment. This lightbulb moment led me to pursue a doctorate in education policy, so I can now use assessment as a tool to influence educational systems and policies.

Grit and determination are etched in my genealogical trail. My grandparents escaped North Korea on top of a train, and my mother emigrated to the US to acquire her computer science degree, whilst working two jobs and raising me. My gratitude for my mum is infinite. She taught me the value of hard work, power of education and wisdom of love. I am also grateful for family, friends and colleagues who make the journey much lighter and brighter; it takes a village to cultivate success!

While I love research, I enjoy activities such as yoga, meditation, gardening and spending time with family, friends and my $100-\mathrm{lb}$ dog.

\section{PATHWAY FROM SCHOOL TO SOCIAL SCIENCE}

Christina and Valentina emphasise the value of an interdisciplinary skillset, including science and humanities. A career in social science can be approached from many directions, but Christina suggests mathematics and psychology as especially useful subjects to take.

Social science is very broad and can include many other aspects aside from Christina and Valentina's focus areas, such as economics or geography. As Christina's career path indicates, it is sometimes possible to switch from studying humanities to further education in social science.

HOW TO BECOME A SOCIAI SCIENTIST
- According to QS World University Rankings, the best universities
to study social sciences are Harvard, London School of Economics,
Stanford, Oxford, and Cambridge.
- There are apprenticeships available for jobs that involve social science,
such as social work and health care and user-experience research.
- According to salary.com, the average salary for a social scientist in
the US will cover a broad range, depending upon their industry. This
can include universities, local governments, marketing research firms,
think tanks, and non-profit organisations.

\section{HOW DID VALENTINA BECOME AN EXPERT IN INCLUSION?}

In my childhood, I enjoyed playing piano, chasing iguanas and learning languages. I was born in South America and travelled extensively, eventually moving to the US when in middle school. Before then, I had grown up in an area where most people looked like me and shared cultural practices - I only became aware of prejudice and discrimination when I arrived in the US. I developed a keen interest in why these dynamics occurred, which led to my academic career.

My life experiences have truly informed my work. I left my country at a time of political turmoil, and transitioned from prestigious Latin American private schools to a series of North American public schools that radically changed my worldview and challenged my identities. My awakening continued well into my years as an undergraduate and graduate student. I would go on to become a US citizen and receive two bachelor's, a master's, a Ph.D., and professional certificates, while managing the impostor syndrome and racial battle fatigue that stemmed from decades of micro-aggressive stress in invalidating environments. These profound experiences shaped my practice and continue to advance my work. My parents also inspired my career from very early on. My dad was a cardiovascular anaesthesiologist committed to providing excellent medical care to people from disadvantaged socioeconomic backgrounds. My mom has worked with many illustrious organisations, such as NASA. Currently, she spends a lot of time helping under-represented communities have a voice in the politics of our city by providing simultaneous translation.

My success stems from determination, grit and passion for what I do. I also have a love of literature, which I focused on for my doctorate; literature can be like a nation's private diary, providing vivid insights into its inner workings and culture.

My children fill my life with joy and provide great perspective. I have great hope for future generations! 